\title{
The Effect of Dioscorea alata Extract on the Early Development of Zebrafish Embryo (Danio rerio) and Rasbora lateristriata
}

\author{
Anita Raharjeng and Bambang Retnoaji *
}

\begin{abstract}
Department of Biology, Faculty of Biology, Universities Gadjah Mada. Yogyakarta, Indonesia. *Corresponding author. Email: bambang.retnoaji@ugm.ac.id
\end{abstract}

\begin{abstract}
Dioscorea alata is reported to have many benefits and potentials, one of which is anti-diabetes since it contains Dioscorin and Glucomannan. D. alata used in this research is purple cultivar since it has higher antioxidant content than the other cultivar. This research will examine D. alata extract's effects on the early development of zebrafish (Danio rerio) and yellow rasbora (Rasbora lateristriata) embryos. The D. rerio and R. lateristriata embryos treatment was carried out on 3 hours post-fertilization (hpf) embryos aged. The embryos were exposed to D. alata, with $100 \mathrm{mg} / 100 \mathrm{ml}, 500 \mathrm{mg} / 100 \mathrm{ml}$, and $1000 \mathrm{mg} / 100 \mathrm{ml}$. Biocompatibility assessment was carried out by measuring the hatching rate, survival rate, morphological changes, and heartbeat rate, respectively. The hatching rate was determined as the number of embryos that hatched at observation time. The survival rate was determined by the number of survive embryos at $12,24,36,48,60$, 72 and 84 hpf, respectively. Moreover, the morphological change was observed on the shape of the embryo's heart and yolk and the tail-yolk detachment as an indicator of a normal body wall occurrence, respectively. Moreover, the physiological performance was decided base on the heartbeat rate performance of the embryos. Statistical analysis was performed by using the SPSS 21 application. One-way ANOVA was used to assess the significance of the effect of treatment on outcomes. The result showed a significant effect of D. alata on the hatching rate and survival rate, but it does not effect the embryo morphology and the heart rate in all treatments to Rasbora lateristriata and Danio rerio.
\end{abstract}

\section{Keywords: Millennial generation, Creative industry, Poverty}

\section{INTRODUCTION}

Dioscorea alata is a well-known dioscoreaceae group and is one of the third major tubers in the world cultivated in the tropics [1]. Also, D. alata tubers are known to have high potential as medicinal plants because they have anticancer, anti-diabetes, and anti-microbial properties. This plant is also known to be used in various treatments such as laxatives, worm medicine, antioxidants, cough medicine, diarrhea medicine, treating fever, gonorrhea, leprosy, liver, hemorrhoids and even curing tumors and cancer [2]. This plant is also rich in nutrients and bioactive compounds, namely carbohydrates $(6.8 \%)$, fiber $(4.01 \%)$, protein $(2.81 \%)$, saponins $(2.56 \%)$, flavonoids $(1.32 \%)$, fat $(0.81 \%)$, tannins $(0.66 \%)$ and alkaloids $(0.51 \%)$.
The diosgenin content in D. alata is known to be widely used as a precursor in the synthesis of steroid hormones such as progesterone, corticosteroids, and anabolic steroids. The main saprogenic groups are diosgenin and yamogenin [3]. Other bioactive compounds that are also present in D. alata such as phenol, allantoin, dioscorin, sapogenin, prosapogenin, gracilin, choline, L-arginine, and polysaccharide [4]-[6] .

The lack of data on the toxic effects of consumption of $\mathrm{D}$. alata makes research on the effects of exposure to D. alata extract at the early stages of embryo development of Danio rerio and Rasbora lateristriata is necessary. Further testing on test animals is essential to determine the safety of their use. The research results are expected to provide information related to LD50 and the use of the right 
dosage and can identify signs of toxicity that occur. The toxicity test is one of the preclinical tests, in which chemical compounds are tested on experimental animals before being tested on humans [7].

Danio rerio is a tropical freshwater domesticated fish belonging to the Cyprinidae family of the small Cypriniformes order which is generally used for developmental biology, embryology and toxicology research [8]. Danio rerio has a simple vascular system and a heart consisting of the sinus venous, atria, ventricles and bulb arteriosus connected. This heart can be observed 24 hours after fertilization (HPF) occurs. In $120 \mathrm{hpf}$, other organs such as brain, liver, pancreas and kidneys are fully developed [9]. The gene can be modified to produce transgenic or mutant individuals for research purposes [10]. This uniqueness makes Danio rerio an efficient animal research model and can be suitable for many studies.

Rasbora lateristriata is a type of local freshwater fish in Indonesia, popular, adaptable, and highly resistant to adverse environmental conditions [11]. Rasbora lateristriata from the genus Rasbora has been widely used in freshwater bioindicator research. This fish is used as an environmental indicator to assess habitat degradation or ecological health [12]. This species is also used as consumption fish. Rasbora lateristriata is widespread in Southeast Asia and is relatively easy to breed and has many eggs up to more than 200 eggs per female broodstock. The large number of eggs produced from this Rasbora lateristriata guarantees an abundance of eggs to be observed concerning research on toxicity testing in embryos and larvae.

\section{METHODOLOGY}

\subsection{Location}

This research was conducted in the Lab. Structure of Animal Development, Faculty of Biology, UGM. This study used a randomized block design (RBD), each treatment was repeated 3 times. The subjects of the study were Danio rerio and Rasbora lateristriata embryos which were divided into 3 treatment groups and 1 control group.

\subsection{Danio rerio maintenance and egg collection}

The animal used in this study was the Danio rerio Wild Type from Leiden University and then bred at the Faculty of Biology UGM. Danio rerio is maintained in standard conditions, namely on a cycle of 14-10 light-dark with a temperature of 27-28.5 ${ }^{\circ} \mathrm{C}$, dissolved oxygen levels around 6-8, and fed 3 times a day (morning 8-9, noon 1213 , afternoon 15-16). Fish are reared until they are ready to be spawned. One day before spawning, the fish are given live food (Artemia salina) twice a day, namely in the afternoon and evening. Group of females and males used 2: 3. After spawning, fertilization is indicated to occur during the early morning sun exposure. Danio rerio eggs were collected from the matting chamber and transferred to a Petri dish. Only good quality, fertilized eggs were used in this study.

\subsection{Maintenance of Rasbora lateristriata and collecting eggs}

The animal used in this research is local Rasbora lateristriata bred at the Faculty of Biology UGM. Rasbora lateristriata is maintained in standard conditions, namely on a cycle of 14-10 light-dark with a temperature of 27$28.5^{\circ} \mathrm{C}$, dissolved oxygen levels around $6-8$, and given 3 meals a day (morning 8-9, noon 12-13, afternoon 15-16). Fish are reared until they are ready to be spawned. Rasbora lateristriata was spawned in the spawning tub using palm fiber, the volume of incoming water was regulated, and the female and male groups used were 1: 2. After spawning, fertilization is indicated to occur during the early morning sun exposure. Eggs of Rasbora lateristriata were collected from the spawning pond and transferred in a Petri dish. Only good quality, fertilized eggs were used in this study.

\subsection{Dioscorea alata preparation}

D.alata used in this study is a purple cultivar obtained from the Dieng highlands, Central Java. The tubers are washed, peeled and cut into small pieces. They are then dried at $50^{\circ} \mathrm{C}$ using an oven, mashed and sieved on a sieve with $60 \mathrm{mesh}$. After that, stored in airtight packaging and put in the refrigerator at $4^{\circ} \mathrm{C}$ until ready to use. When used, D.alata powder is dissolved in egg water, then stirred, filtered and prepared on a well-plate to immerse the fish embryos.

\subsection{Treatment of D. alata on Embryo Danio rerio and Rasbora lateristriata}

Toxicity tests were carried out in accordance with Fish Embryo Toxicity (FET) 236 guidelines prepared by the Organization for Economic Co-operation and Development (OECD, 1997). The fertilized embryos were transferred to the well-plate using a pipette. Then the embryos are immersed in freshly made egg water. 1 liter of egg water contains 1.5 salt stock +1 drop of methylene blue (as an anti-fungal). Powder material of D. alata was prepared in three concentrations, namely $100 \mathrm{mg}$ (treatment A), 500mg (treatment B) and $1000 \mathrm{mg} / 100 \mathrm{ml}$ (treatment C) respectively in egg water, and one control. 10 Rasbora lateristriata embryos were used at each concentration of D. 
alata and control, with 3 replications each, so that a total of 120 embryos total.

\subsection{Embryo Evaluation of Danio rerio and Rasbora lateristriata}

Fish embryos were observed and compared between control and treatment groups at 6, 12, 24, 36, 48, 60, 72, and $84 \mathrm{hpf}$ through direct observation and using the Leica DM750 microscope. During the treatment period, to calculate the level of biological defects, the number of non-hatching and dead eggs and abnormal larvae was recorded. After treatment, biocompatibility assessment was carried out by looking at the survival rate (SR), which was determined from the number of live embryos at each hour of observation compared to the total number of embryos. The hatching rate was determined by the number of eggs hatched per hour of observation compared to the total number of embryos. In addition to calculating the level of biological defects, the number of eggs that did not hatch and died and abnormal larvae was recorded. There are 4 indicators of embryo mortality, namely: (1) the occurrence of coagulation in fertilized eggs, (2) disturbed somite formation, (3) disruption in the release of the tail from the yolk, and (4) disturbances in heart rate (OECD, 1997). Also the indicators for normal embryo development are; formation of otic placode, brain blockage, and pigmentation in the embryo's body.

\subsection{Data Collection}

Embryos that were given control treatment and D.alata solution were observed using a Leica DM750 microscope. Hatching rate (HR), survival rate (SR) and heart rate were analyzed quantitatively. Meanwhile, embryonic development data regarding morphological form were analyzed qualitatively. Embryo development was observed at $6,12,24,36,48,60,72$, and $84 \mathrm{hpf}$ by observing each change and compared to the control group.

\subsection{Statistic Analysis}

Statistical analysis was performed using IBM SPSS Statistics 21 software. One Way ANOVA test was used to determine differences between treatment groups with various concentrations of D. alata. Data were presented as mean \pm standard deviation and were considered significant if $\mathrm{P}<0.05$. The Duncan test was carried out to test the differences between treatments.

\section{RESULTS AND DISCUSSION}

There is little difference between the embryos of Danio rerio and Rasbora lateristriata, and this is thought to be due to the different fertilization periods. The development of the Rasbora lateristriata embryo was faster, presumably because the fertilization of Rasbora lateristriata occurred earlier than Danio rerio. In this study, the fertilized embryos were immediately transferred to the well-plate for treatment. The treatment is given in the gastrulation phase so that it is known whether the material used as treatment gives disturbance to the embryo or not.

\subsection{Effect of D. alata on Embryo Development of Danio rerio and Rasbora lateristriata}

The stages of embryonic development of Rasbora lateristriata and Danio rerio begin when fertilization occurs. After fertilization occurs, the eggs swell, and zygotes are formed. After that, a perivitelline space is formed, characterized by the accumulation of the cytoplasm at one of the egg poles, thus forming a blast disc that is easily distinguished from the yolk. Partial cleavage (meroblastic cleavage) occurs, resulting in 2 cells occurring at 30 minutes after fertilization (HPF) and followed by a second division at 40hpf minutes. This second division occurs meridional from the right angle of the division to produce 4 germ cells. The 16 cell stage occurs at $1.5 \mathrm{hpf}$ [13].

At 6hpf there is still a gastrulation phase, the phase of embryonic development where a single-layered blastula is arranged into a layered structure. In this phase, the process of neurulation and organogenesis has not yet occurred. When given exposure to certain substances, it can be known that the material used as a treatment causes a disturbance or not to the embryo.

The treatment was carried out at $3 \mathrm{hpf}$, then at $6 \mathrm{hpf}$, the first checking was carried out after exposure. In the 6 hours post fertilization (HPF) observation, both Rasbora lateristriata and Danio rerio embryos in all treatments, the embryos were still in the epibolic stage as shown in Figure 1 below.

Figure 1 shows that at $6 \mathrm{hpf}$ it is suspected that there is no influence of D. alata on the development of Rasbora lateristriata and Danio rerio eggs. At $12 \mathrm{hpf}$ it began to appear that there were differences in development, namely control Rasbora lateristriata, treatment A (100mg / 100ml) and treatment B $(500 \mathrm{mg} / 100 \mathrm{ml})$, there was an organogenesis phase with de-tailed yolk, but in treatment C (1000mg / 100ml) and all Danio rerio's embryo is still in the epibolic phase of the gastrula. 


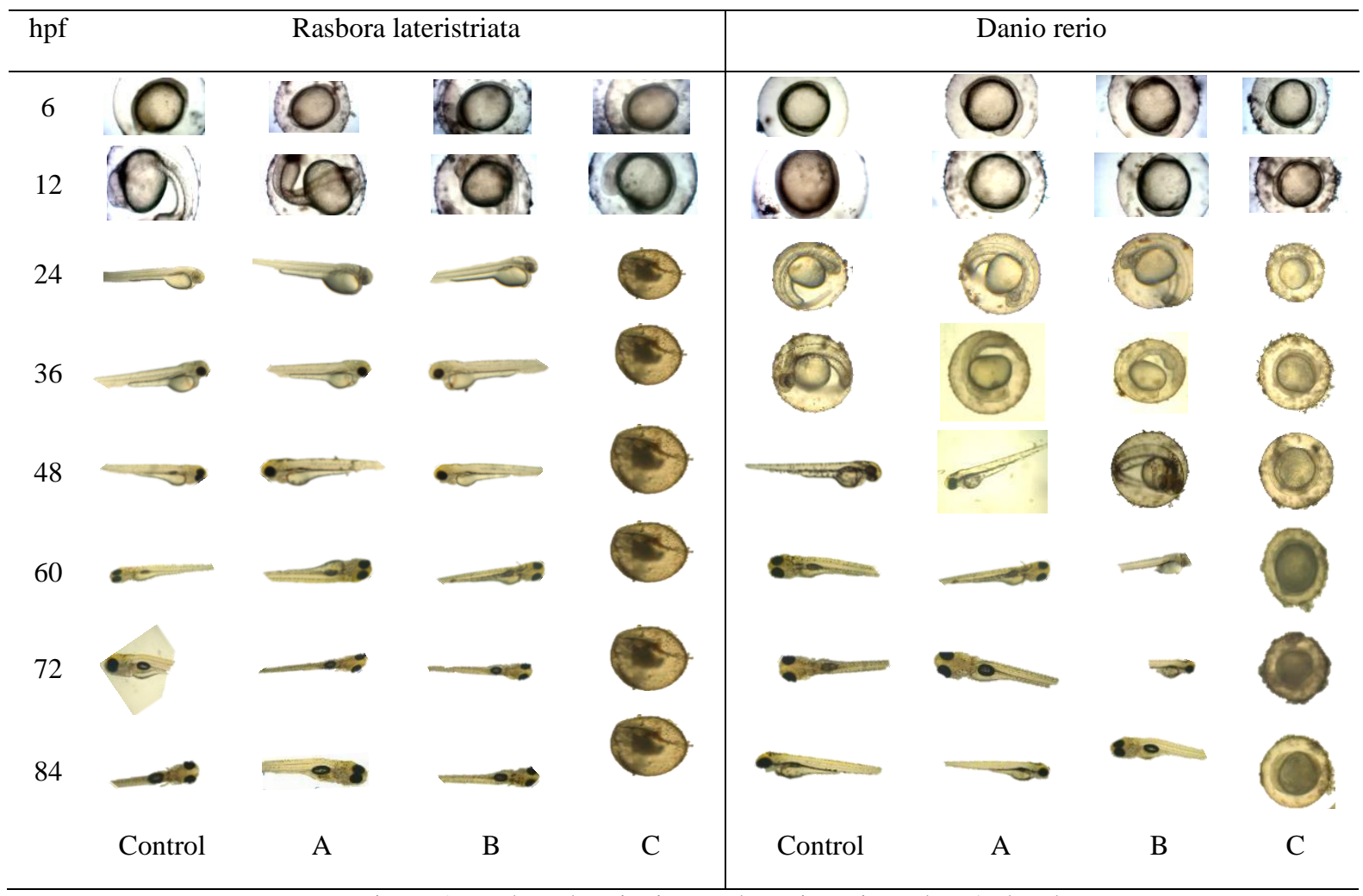

Figure 1. Rasbora lateristriata and Danio rerio embryo's development

There was a delay in the development of Rasbora lateristriata in treatment C. In theory, at the age of $12 \mathrm{hpf}$, the Rasbora lateristriata embryo's head and the tail was clearly different because $12 \mathrm{hpf}$ was the final gastrulation phase. The notochord is formed at the age of 14hpf, which is indicated by the presence of somite's.

The eye lens has formed and the heart begins to form [14]. Meanwhile, the embryo of Danio rerio aged 12hpf has only 5 somites, optic and cupper vesicles have begun to form [15]. From these observations, it can be concluded that the embryo development of Rasbora lateristriata is faster than that of Danio rerio.

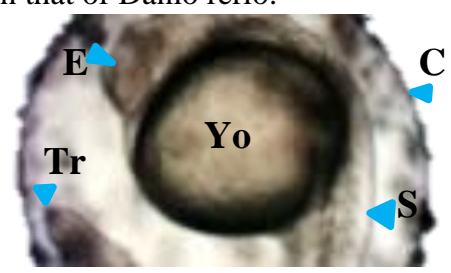

Figure 2. Embryo Rasbora lateristriata $12 \mathrm{hpf}$ treatment B (500mg/100ml D. alata)
E: eyes, Yo: yolk, Tr: Tail region, S: Somite, C: Corion

Figure 2 above shows that the eyes, tail, and somite's have formed, but the heart and the vesicle cuppfer are still not visible. This proves that the condition of the $12 \mathrm{hpf}$ Rasbora lateristriata embryo treatment B (500mg / 100ml) is in line with the theory. The cloudy color in the image of 12hpf Rasbora lateristriata embryo treatment B $(500 \mathrm{mg} /$ $100 \mathrm{ml}$ ) is D. alata, whose granules stick to the embryo's chorion. The factor that causes the differences in embryonic development of Rasbora lateristriata and Danio rerio is because genetically, Rasbora lateristriata has a faster embryo development than Danio rerio, so it is possible for Rasbora lateristriata to be proposed as one of the experimental animals in the future. Also, Rasbora lateristriata has a higher number of embryos than Danio rerio, thus ensuring abundant availability of embryos. 


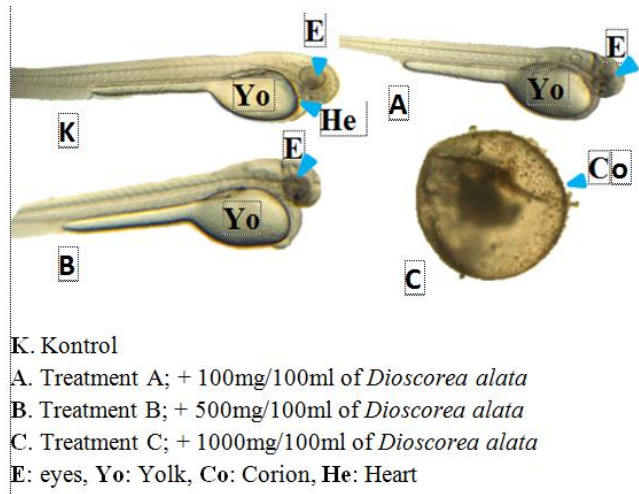

Larva Rasbora lateristriata $24 \mathrm{hpf}$

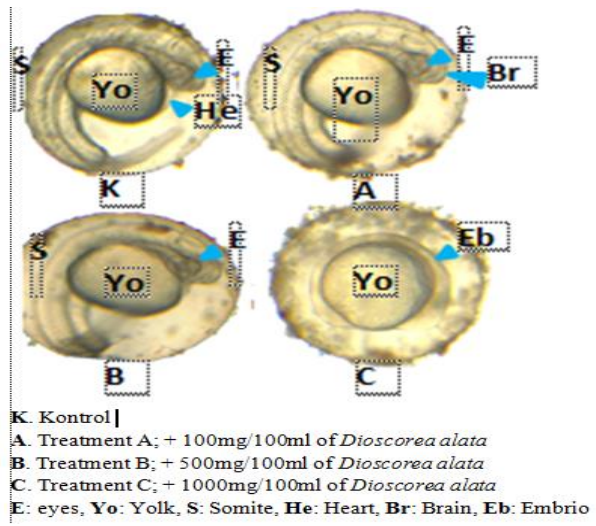

Embrio Danio rerio 24hpf

Figure 3. Larva of Rasbora lateristriata and embryo of Danio rerio aged $24 \mathrm{hpf}$

The next observation is at the age of $24 \mathrm{hpf}$ for Rasbora lateristriata and Danio rerio. As shown in Figure 3, the larvae of Rasbora lateristriata embryos in treatment $\mathrm{C}$ (1000mg / 100ml) showed the damaged condition of Rasbora lateristriata eggs and there was a hole in the chorion, which indicated that the eggs had undergone lysis on 10 repeated eggs of Rasbora lateristriata. Whereas in the control treatment, A and B all Rasbora lateristriata embryos had hatched under normal conditions. The hatch conditions of the control treatments, $\mathrm{A}$ and $\mathrm{B}$, are in line with the theory, which at the age of 24-25hpf Rasbora lateristriata will hatch in water conditions with a temperature of $28.5-30{ }^{\circ} \mathrm{C}$ [16]. The 24hpf phase is the pre-larval phase which is indicated by the presence of an almost round yolk membrane located anteriorly and ventrally. You can clearly see the mouth, anus and gastrointestinal tract like a tube. The head appears smaller than the body, but the eyes appear large.

In Figure 3, for Danio rerio embryos, the conditions of the embryos in the control treatment, $\mathrm{A}$ and $\mathrm{B}$ are in accordance with the theory, namely the $24 \mathrm{hpf}$ Danio rerio embryo has an embryo size of $1.9 \mathrm{~mm}$ with a head rotation of 120 degrees, pigmentation has occurred in the retina and skin, there is a crease. On the middle fin, you can see the presence of red blood cells in the yolk and the heart rate has begun to be detected, but the heart rate cannot be calculated [16]. But unfortunately, in treatment $\mathrm{C}$ the conditions were still not in accordance with the theory. The condition of the embryos in treatment $\mathrm{C}$ was similar to the states at age 6 and $12 \mathrm{hpf}$. This indicates that the embryo has a delay or delay in its development. At 96hpf observation (data are not shown), embryo Danio rerio of treatment $\mathrm{C}$ experienced death as indicated by tearing of the chorion and embryo lysis.

All Rasbora lateristriata's embryos in treatment C $(1000 \mathrm{mg}$ / 100ml) at 24hpf died, and the Danio rerio embryos at 24 hpf suffer from developmental delay. On 96hpf, all Danio rerio embryos die. This fact showed that $\mathrm{D}$. alata stress at high concentrations had a lethal effect on the embryo of Rasbora lateristriata and Danio Rerio.

The high stress of D. alata which results in death and delay in embryo development is probably due to the presence of toxic components in D. alata. In this study, the D. alata used was the raw one. After peeling and washing D. alata, D. alata is dried and blended to make powder. After that, it was used to be tested on R.lateristriata and D. rerio embryos. This raw D. alata turns out to contain toxins, these toxic substances are oxalates, phenols, cyanide acid, tannins, amylase inhibitors and trypsin inhibitors [17],[18]. One of the poisons in D. alata is cyanide acid. Cyanide acid or $\mathrm{HCN}$ is toxic because it can interfere with the transport of oxygen in the body. $\mathrm{HCN}$ binds to the mitochondrial cytochrome oxidase enzyme which will then block the use of oxygen in cellular metabolism (ATSDR, 2014). If cells do not get oxygen, of course, these cells will die immediately.

Another toxin contained in D. alata and likely involved in the process of embryo destruction is tannins. On the cell membrane, tannins bind to plasmalemma proteins and form ionic channels in the lipid membrane. Electrostatically, tannins will be tethered to the outer protein-membrane and not the $\mathrm{Ca} 2+$ channels on the cell membrane. Cells that have been blocked by their $\mathrm{Ca} 2+$ channels will experience damage and die [19].

So that in R.lateristriata and D. rerio embryos with high exposure to D. alata, the embryos could not survive and even die before hatching because the toxins from $\mathrm{HCN}$ and tannins were quite strong.

\subsection{Effect of D. alata on embryo survival rate}

The following formula calculates the survival rate;

$\mathrm{SR}=\frac{\mathrm{Nt}}{\mathrm{No}} \times 100 \%$

$\mathrm{SR}=$ Survival Rate 
$\mathrm{Nt}=$ number of fish alive during the study

No $=$ number of fish at the beginning of the study

This study used 10 Rasbora lateristriata embryos with three independent experiments. The total number of Rasbora lateristriata embryos used was 120 . Figure and Graph 3.1 show that $100 \%$ of embryos can survive at $6 \mathrm{hpf}$. Up to $48 \mathrm{hpf}$ the survival rate of control Rasbora lateristriata is still $100 \%$, which is different from the C treatment fish, which only lasts up to 6hpf, then all the fish in treatment $\mathrm{C}$ all die. At $24 \mathrm{hpf}$, treatment $\mathrm{A}$ and $\mathrm{B}$ experienced a decrease in survival rate up to $96 \%$, then decreased again at $36 \mathrm{hpf}$ and $48 \mathrm{hpf}$, reaching $96 \%$ for treatment $\mathrm{A}$ and $93 \%$ for treatment $\mathrm{B}$. Then there was another decrease in the survival rate at $60 \mathrm{hpf}$ observation reaching $93 \%$ for control and $\mathrm{A}$, and in treatment $\mathrm{B}$ of $83 \%$. The survival rate continued to decline until the last observation at $84 \mathrm{hpf}$ of $90 \%, 86 \%$ and $80 \%$ in the control treatment, $\mathrm{A}$ and $\mathrm{B}$. The survival of Rasbora lateristriata embryos in the control and exposure to $\mathrm{D}$. alata showed a significant difference $(\mathrm{P}<0.05)$.

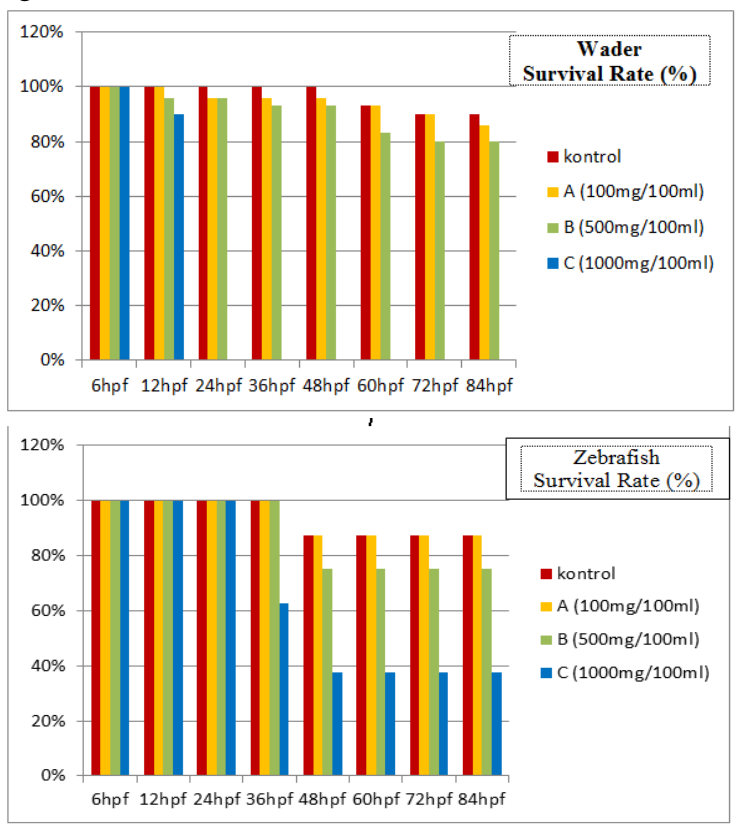

Figure 4 Survival rate on Embryo and Larva Rasbora lateristriata and Danio rerio exposed to D. alata

Figure 4 show that $100 \%$ of Rasbora lateristriata embryos can survive at 6 to $24 \mathrm{hpf}$. Up to $36 \mathrm{hpf}$, the survival rate of Danio rerio control, A and B is still $100 \%$, while C has a decrease in the survival rate of $63 \%$, then decreases again at $48 \mathrm{hpf}$ and $60 \mathrm{hpf}$ to reach $88 \%$ for control and A treatments, while for treatment $\mathrm{B}$ and $\mathrm{C}$ it becomes $75 \%$ and $38 \%$. Furthermore, for control treatment and A were still the same until the end of the observation period, namely $88 \%$, treatment B decreased to $75 \%$ until the end of the observation. In treatment, $\mathrm{C}$ decreased to $38 \%$ until the end of the observation period.
Danio rerio embryo survival in control and exposure to D. alata showed a significant difference $(\mathrm{P}<0.05)$. There are differences in the survival of embryos and larvae between Rasbora lateristriata and Danio rerio in the control treatment, A, B and C. There is a delay in embryo development of Rasbora lateristriata and Danio rerio since the age of $12 \mathrm{hpf}$ in treatment $\mathrm{C}$, which then died and destroyed itself. D. alata exposure caused death in all embryos in treatment $\mathrm{C}$.

The ANOVA statistical test $(\mathrm{p}<0.05)$, showed that the exposure to D. alata had a significant effect on the survival rate of the embryo and larvae between Rasbora lateristriata and Danio rerio, in each treatment, at several fish ages. The Duncan test was carried out as a further test to see the effect between treatments at each observation time, as shown in Table 1.

Table 1.Embryonic and larval survival rates between $\mathrm{R}$. lateristriata and D. rerio, in each treatment, at several ages

\begin{tabular}{lcccc}
\hline Hpf & Control & A & B & C \\
\hline W6 & $10.0^{\mathrm{c}}$ & $10.0^{\mathrm{b}}$ & $10.0^{\mathrm{b}}$ & $10.0^{\mathrm{a}}$ \\
$\mathrm{W} 12$ & $10.0^{\mathrm{C}}$ & $10.0^{\mathrm{b}}$ & $9.7^{\mathrm{ab}}$ & $0.0^{\mathrm{a}}$ \\
$\mathrm{W} 24$ & $10.0^{\mathrm{C}}$ & $10.0^{\mathrm{b}}$ & $10.0^{\mathrm{ab}}$ & $0.0^{\mathrm{a}}$ \\
$\mathrm{W} 36$ & $10.0^{\mathrm{C}}$ & $9.7^{\mathrm{b}}$ & $9.3^{\mathrm{ab}}$ & $0.0^{\mathrm{a}}$ \\
$\mathrm{W} 48$ & $10.0^{\mathrm{c}}$ & $9.7^{\mathrm{b}}$ & $9.3^{\mathrm{a}}$ & $0.0^{\mathrm{a}}$ \\
$\mathrm{W} 60$ & $9.3^{\mathrm{bc}}$ & $8.3^{\mathrm{ab}}$ & $9.3^{\mathrm{a}}$ & $0.0^{\mathrm{a}}$ \\
$\mathrm{W} 72$ & $9.0^{\mathrm{bc}}$ & $8.0^{\mathrm{ab}}$ & $9.0^{\mathrm{a}}$ & $0.0^{\mathrm{a}}$ \\
$\mathrm{W} 84$ & $9.0^{\mathrm{bc}}$ & $8.0^{\mathrm{ab}}$ & $8.7^{\mathrm{a}}$ & $0.0^{\mathrm{e}}$ \\
$\mathrm{Z} 6$ & $8.0^{\mathrm{ab}}$ & $8.0^{\mathrm{ab}}$ & $8.0^{\mathrm{b}}$ & $8.0^{\mathrm{d}}$ \\
Z12 & $8.0^{\mathrm{ab}}$ & $8.0^{\mathrm{ab}}$ & $8.0^{\mathrm{b}}$ & $8.0^{\mathrm{d}}$ \\
Z24 & $8.0^{\mathrm{ab}}$ & $8.0^{\mathrm{ab}}$ & $8.0^{\mathrm{b}}$ & $8.0^{\mathrm{d}}$ \\
Z36 & $8.0^{\mathrm{ab}}$ & $8.0^{\mathrm{ab}}$ & $8.0^{\mathrm{b}}$ & $5.0^{\mathrm{c}}$ \\
Z48 & $7.0^{\mathrm{a}}$ & $7.0^{\mathrm{a}}$ & $6.0^{\mathrm{ab}}$ & $3.0^{\mathrm{b}}$ \\
Z60 & $7.0^{\mathrm{a}}$ & $7.0^{\mathrm{a}}$ & $6.0^{\mathrm{ab}}$ & $3.0^{\mathrm{b}}$ \\
Z72 & $7.0^{\mathrm{a}}$ & $7.0^{\mathrm{a}}$ & $6.0^{\mathrm{ab}}$ & $3.0^{\mathrm{b}}$ \\
Z84 & $7.0^{\mathrm{a}}$ & $7.0^{\mathrm{a}}$ & $6.0^{\mathrm{ab}}$ & $3.0^{\mathrm{b}}$ \\
\hline
\end{tabular}

The factor causing the delay in embryo development in this study is thought to be due to the enzyme amylase inhibitor and trypsin inhibitor in D. alata. The amylase inhibitor enzyme's presence is known to be a form of selfdefense of D. alata from its predators using an amylase inhibitor mechanism that will inhibit starch reform and sugar-binding. This amylase inhibitor enzyme will increase the hydrolysis of the $\alpha$ - $(1,4)$ starch glycosidation pathway. Amylase inhibitor enzymes are also called "carbo-blockers" because of their ability to inhibit the process of breaking down carbohydrates. Also, complex carbohydrates will be immediately discarded or 
eliminated, even though they should still be stored in the body as fat [20].

Also, trypsin inhibitors in D. alata also worsen the situation because trypsin inhibitors will inhibit protein breakdown [21]. Therefore, trypsin inhibitors are considered as anti-nutritional factors or ANF. Apart from that, trypsin inhibitors also interfere with the function of chymotrypsin. Chymotrypsin itself is a catalyst that helps break peptide bonds with a hydrolysis reaction [22].

Unlike the HCN and tannin toxins that work quickly and interfere with the hatching process, the embryos of $\mathrm{R}$. lateristriata and D. rerio that have successfully hatched still have to face other toxins in the form of amylase inhibitor enzymes and trypsin inhibitor enzymes. These two enzymes will interfere with the digestion of R. lateristriata and D. rerio larvae. When two enzymes' workings, the larvae of R.lateristriata and D. rerio will lose weight and then die thin. This theory is in line with this research that fish death occurs gradually, not all at once.

\subsection{Effect of Dioscorea alata on embryo hatching rate}

The following formula calculates the hatching rate;

$\mathrm{HR}=\frac{\mathrm{Nt}}{\mathrm{No}} \times 100 \%$

$\mathrm{HR}=$ Hatching Rate

$\mathrm{Nt}=$ number of eggs hatched during the study

No $=$ total number of eggs at the start of the study

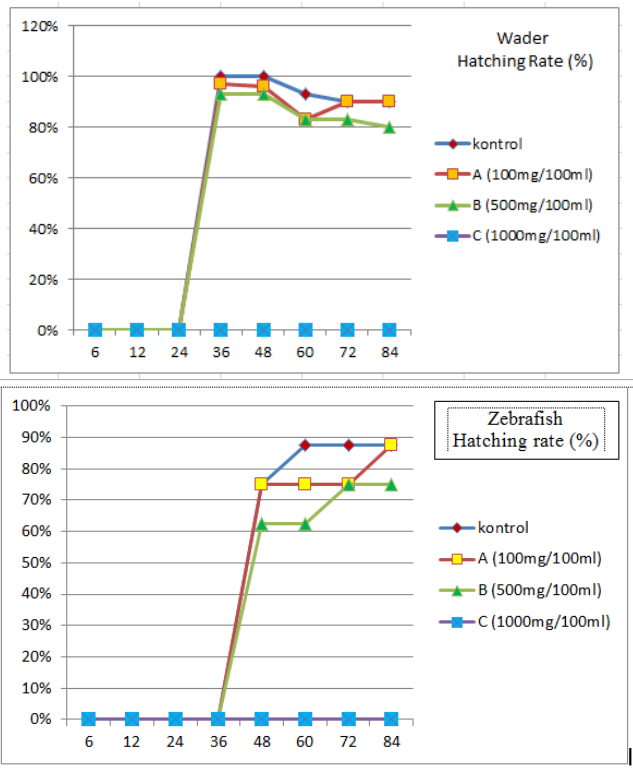

Figure 5 Hatching rate of Rasbora lateristriata and Danio rerio's embryos exposed to D. alata
Hatchability of eggs is the eggs' ability to develop in the process of embryogenesis until the eggs hatch. The hatchability of eggs is influenced by several factors, including the quality of the eggs themselves. In contrast, the fertility of eggs is related to the ability of the sperm to fertilize an egg and the quality of water. Hatchability is an indicator in determining the success of hatching.

Figure 5 show that Rasbora lateristriata began to hatch at the age of 36hpf, which is slightly different from the literature that Rasbora daniconius hatched at the age of 24$25 \mathrm{hpf}$ [16]. The difference in hatching time is thought to be due to differences in the species used between the literature and those used in this study.

In this study, control Rasbora lateristriata embryos, treatment A and B successfully hatched $100 \%$ at the age of $36 \mathrm{hpf}$. They then died respectively until the remaining $90 \%, 90 \%$ and $80 \%$ of the embryos were left at the end of th e observation. None of the Rasbora lateristriata embryos in treatment $\mathrm{C}$ were successful.

The hatching rate is the most important indicator for estimating the conditions for the development of embryos in Rasbora lateristriata and Danio rerio. The average hatching period for Rasbora lateristriata embryos is 24$25 \mathrm{hpf}$, while for Danio rerio it is between 48 to $96 \mathrm{hpf}$ [23]. Both Rasbora lateristriata and Danio rerio have embryos surrounded by a chorion during development. The chorion is an acellular envelope made of three layers that cross each other, allowing the material to pass through the embryo by passive diffusion. Chorion has pores or channels with a diameter of $0.5-0.7 \mu \mathrm{m}$ [24]. This layer serves as a protector for the embryo that blocks particles' accumulation due to surface charge interactions [25]. The occurrence of hatch failure in embryos and larvae of Rasbora lateristriata and Danio rerio in treatment $\mathrm{C}$, and hatching delay in embryos of Danio rerio treatment B are thought to be closely related to exposure to D. alata. After statistical analysis, the comparison was significantly different $(\mathrm{P}<0.05)$.

The results of the ANOVA statistical test $(p<0.05)$, showed that the exposure to D. alata had a significant effect on the hatching rate of embryos and larvae between Rasbora lateristriata and Danio rerio, in each treatment, at several fish ages. The Duncan test was carried out as a further test to see the effect between treatments at each observation time as shown in Table 2.

The period before $24 \mathrm{hpf}$ before hatching fish eggs is a critical period for the development of fish larvae. Disorders that occur in the embryonic period before $24 \mathrm{hpf}$ can result in the larvae being born abnormally or even dying. In the successful hatching of fish eggs, temperature and environmental conditions play an essential role. In D. rario, the eggs will hatch at $28^{\circ} \mathrm{C}$, although in $\mathrm{R}$. lateristriata there have been no reports, but it is suspected that the temperature ranges are similar. 
Table 2.Hatching Rate of embryos and larvae between Rasbora lateristriata and Danio rerio in each treatment, at several fish ages

\begin{tabular}{ccccc}
\hline hpf & Control & A & B & C \\
\hline W6 & $0.0^{\mathrm{a}}$ & $0.0^{\mathrm{a}}$ & $0.0^{\mathrm{a}}$ & $0.0^{\mathrm{a}}$ \\
$\mathrm{W} 12$ & $0.0^{\mathrm{a}}$ & $0.0^{\mathrm{a}}$ & $0.0^{\mathrm{a}}$ & $0.0^{\mathrm{a}}$ \\
$\mathrm{W} 24$ & $0.0^{\mathrm{a}}$ & $0.0^{\mathrm{a}}$ & $0.0^{\mathrm{a}}$ & $0.0^{\mathrm{a}}$ \\
$\mathrm{W} 36$ & $10.0^{\mathrm{c}}$ & $12.0^{\mathrm{d}}$ & $10.0^{\mathrm{c}}$ & $9.7^{\mathrm{a}}$ \\
$\mathrm{W} 48$ & $10.0^{\mathrm{c}}$ & $9.7^{\mathrm{d}}$ & $9.3^{\mathrm{c}}$ & $0.0^{\mathrm{a}}$ \\
$\mathrm{W} 60$ & $9.3^{\mathrm{c}}$ & $8.3^{\mathrm{cd}}$ & $9.3^{\mathrm{c}}$ & $0.0^{\mathrm{a}}$ \\
$\mathrm{W} 72$ & $9.0^{\mathrm{c}}$ & $8.0^{\mathrm{cd}}$ & $9.0^{\mathrm{c}}$ & $0.0^{\mathrm{a}}$ \\
$\mathrm{W} 84$ & $9.0^{\mathrm{c}}$ & $8.0^{\mathrm{cd}}$ & $8.7^{\mathrm{c}}$ & $0.0^{\mathrm{a}}$ \\
Z6 & $0.0^{\mathrm{a}}$ & $0.0^{\mathrm{a}}$ & $0.0^{\mathrm{a}}$ & $0.0^{\mathrm{a}}$ \\
Z12 & $0.0^{\mathrm{a}}$ & $0.0^{\mathrm{a}}$ & $0.0^{\mathrm{a}}$ & $0.0^{\mathrm{a}}$ \\
Z24 & $0.0^{\mathrm{a}}$ & $0.0^{\mathrm{a}}$ & $0.0^{\mathrm{a}}$ & $0.0^{\mathrm{a}}$ \\
Z36 & $0.0^{\mathrm{a}}$ & $0.0^{\mathrm{a}}$ & $0.0^{\mathrm{a}}$ & $0.0^{\mathrm{a}}$ \\
Z48 & $6.0^{\mathrm{b}}$ & $6.0^{\mathrm{b}}$ & $5.0^{\mathrm{b}}$ & $0.0^{\mathrm{a}}$ \\
Z60 & $7.0^{\mathrm{b}}$ & $6.0^{\mathrm{b}}$ & $5.0^{\mathrm{b}}$ & $0.0^{\mathrm{a}}$ \\
Z72 & $7.0^{\mathrm{b}}$ & $6.0^{\mathrm{b}}$ & $6.0^{\mathrm{b}}$ & $0.0^{\mathrm{a}}$ \\
Z84 & $7.0^{\mathrm{b}}$ & $7.0^{\mathrm{bc}}$ & $6.0^{\mathrm{b}}$ & $0.0^{\mathrm{a}}$ \\
\hline
\end{tabular}

In this study, there was a significant difference between the hatchability of Rasbora lateristriata and Danio rerio eggs in the control treatment, treatment A, treatment B and treatment $\mathrm{C}$. In treatment $\mathrm{C}$ there were no eggs that successfully hatched. According to literature, failure to hatch fish eggs can be caused by heavy metals. Heavy metals also cause egg penetration, premature penetration, abnormal body shape and even cause death in new larvae and reduce the ability to survive.

D. alata contains heavy metals, such as: cobalt (1.06 - 1.98 / 100g), nickel (0.30 - $0.89 / 100 \mathrm{~g})$, chromium (2.10 - 4.53 / 100g) and lead ( $0.11-0.93 / 100 \mathrm{~g})$ (Padhan, 2018). It is strongly suspected that the heavy metal content in D. alata causes hatching failure in Rasbora lateristriata and Danio rerio.

\subsection{Effect of D. alata on Heart Rate per minute.}

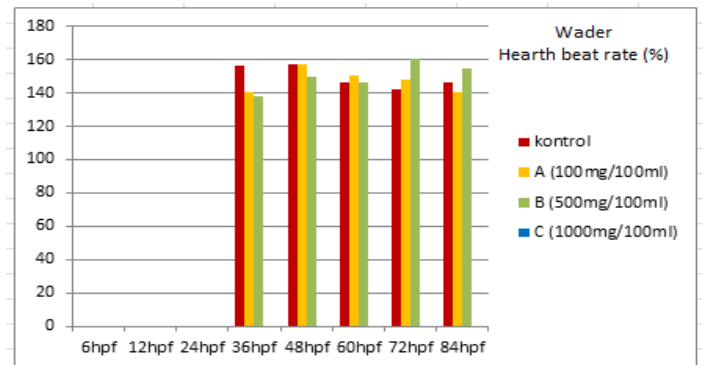

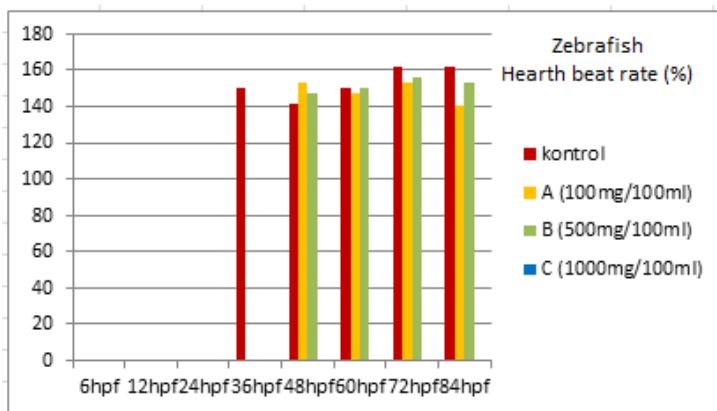

Figure 6 Effect of D. alata various concentrations exposed on the heart rate of Rasbora lateristriata and Danio rerio per minute

The heart is the first organ to form and function in vertebrate embryos. Danio rerio embryo begins to function at $5 \mathrm{hpf}$ in the anterior lateral plate's mesoderm phase and continues until the gastrulation phase. In this phase, the germ layers of the ectoderm, endoderm, and mesoderm are formed. After the gastrulation phase at $10 \mathrm{hpf}$, the linear cardiac tubes begin to contract rhythmically peristalsis at 24 hpf. The valve has not yet formed at this stage, and blood is pumped out at a peak speed of $250 \mathrm{~mm} / \mathrm{s}$ without significant backflow. the lumen begins to open, stroke volume and heart rate increase rapidly at $28 \mathrm{hpf}$ [25]. The heart tube rotates to the left into an S-shape, which displaces the ventricle to the right atrium at $33 \mathrm{hpf}$ [26]. The pumping mechanism moves from a slow peristaltic wave to a sequential contraction chamber, indicating the cardiac conduction system's onset at $36 \mathrm{hpf}$. The ventricular chamber balloon exits with different outer and inner curvatures at $48 \mathrm{hpf}$ [27].

Danio rerio heart rate measurements can be observed at 24,48 , and $72 \mathrm{hpf}$ by counting the heart rate for 30 seconds or 60 seconds under a microscope. Figure 6 show that the entire heart of Rasbora lateristriata and Danio rerio embryo beats over 120 times and a maximum of 160 times in 60 seconds since the age of $36 \mathrm{hpf}$. Heart rate decreased at $48 \mathrm{hpf}$ and increased again at $66 \mathrm{hpf}$ due to the cardiomyocytes' activity starting to delaminate from the ventricular wall to initiate trabeculation and become complete at $72 \mathrm{hpf}$ [27]. Comparison of heart rate in Rasbora lateristriata and Danio rerio in the control treatment and exposure to D. alata showed no significant difference $(\mathrm{P}<0.05)$.

The results of the ANOVA statistical test $(p<0.05)$, showed that $\mathrm{D}$. alata exposure treatment had no significant effect on the heartbeat rate of Danio rerio larvae but had a significant impact on the heartbeat rate of Rasbora lateristriata at the ages of 36, 48, 60, 72 and $84 \mathrm{hpf}$. The Duncan test was carried out as a further test to see the effect between treatments at each observation time, as shown in Table 3 
Table 3. Heart Beat Rate of embryos and larvae between Rasbora lateristriata and Danio rerio, in each treatment, at several fish ages

\begin{tabular}{lcccc}
\hline Hpf & Control & \multicolumn{2}{c}{ A } & \multicolumn{2}{c}{ C } \\
\hline W6 & $0.0^{\mathrm{a}}$ & $0.0^{\mathrm{a}}$ & $0.0^{\mathrm{a}}$ & $0.0^{\mathrm{a}}$ \\
$\mathrm{W} 12$ & $0.0^{\mathrm{a}}$ & $0.0^{\mathrm{a}}$ & $0.0^{\mathrm{a}}$ & $0.0^{\mathrm{a}}$ \\
$\mathrm{W} 24$ & $0.0^{\mathrm{a}}$ & $0.0^{\mathrm{a}}$ & $0.0^{\mathrm{a}}$ & $0.0^{\mathrm{a}}$ \\
$\mathrm{W} 36$ & $156.0^{\mathrm{cd}}$ & $12.0^{\mathrm{bc}}$ & $156.0^{\mathrm{b}}$ & $141.7^{\mathrm{a}}$ \\
W48 & $160.0^{\mathrm{d}}$ & $162.0^{\mathrm{cd}}$ & $148.0^{\mathrm{cd}}$ & $0.0^{\mathrm{a}}$ \\
$\mathrm{W} 60$ & $146.0^{\mathrm{b}}$ & $150.0^{\mathrm{bc}}$ & $146.0^{\mathrm{bc}}$ & $0.0^{\mathrm{a}}$ \\
$\mathrm{W} 72$ & $142.0^{\mathrm{b}}$ & $148.0^{\mathrm{bc}}$ & $160.0^{\mathrm{e}}$ & $0.0^{\mathrm{a}}$ \\
W84 & $146.0^{\mathrm{b}}$ & $140.0^{\mathrm{b}}$ & $154.0^{\mathrm{cde}}$ & $0.0^{\mathrm{a}}$ \\
Z6 & $0.0^{\mathrm{a}}$ & $0.0^{\mathrm{a}}$ & $0.0^{\mathrm{a}}$ & $0.0^{\mathrm{a}}$ \\
Z12 & $0.0^{\mathrm{a}}$ & $0.0^{\mathrm{a}}$ & $0.0^{\mathrm{a}}$ & $0.0^{\mathrm{a}}$ \\
Z24 & $0.0^{\mathrm{a}}$ & $0.0^{\mathrm{a}}$ & $0.0^{\mathrm{a}}$ & $0.0^{\mathrm{a}}$ \\
Z36 & $150.0^{\mathrm{a}}$ & $0.0^{\mathrm{a}}$ & $0.0^{\mathrm{a}}$ & $0.0^{\mathrm{a}}$ \\
Z48 & $141.0^{\mathrm{a}}$ & $153.0^{\mathrm{a}}$ & $0.0^{\mathrm{a}}$ & $0.0^{\mathrm{a}}$ \\
Z60 & $150.0^{\mathrm{a}}$ & $147.0^{\mathrm{a}}$ & $0.0^{\mathrm{a}}$ & $0.0^{\mathrm{a}}$ \\
Z72 & $162.0^{\mathrm{a}}$ & $153.0^{\mathrm{a}}$ & $156.0^{\mathrm{a}}$ & $0.0^{\mathrm{a}}$ \\
Z84 & $162.0^{\mathrm{a}}$ & $140.0^{\mathrm{a}}$ & $153.0^{\mathrm{a}}$ & $0.0^{\mathrm{a}}$ \\
\hline
\end{tabular}

Heartbeat rate in fish is closely related to oxygen consumption and swimming speed. Unfortunately, this study did not check the swimming speed and oxygen consumption of Rasbora lateristriata and Danio rerio, but this is most likely due to physiological compensation due to circulation and the hemostasis process [28]. The heart muscle, nerves strongly influence the heartbeat rate, and blood vessels, locomotor and movement involving the structure and function of the muscles, brain, skeleton, and nerves, both of which are derivatives of the ectoderm and mesoderm germinativum layers [29].

In this study, it appears that morphologically no damage occurs in the growth of embryos and larvae of Rasbora lateristriata and Danio rerio both in the control treatment and the exposure treatment of D. alata. Larvae that had successfully hatched and their heart rate could be counted showed normal growth, although zebrafish larvae at concentration B $(500 \mathrm{mg} / 100 \mathrm{ml})$ experienced a delay in hatching, but in general, it did not affect their average heartbeat.

\subsection{Effect of D. alata on Morphology of Larvae Rasbora lateristriata and Danio rerio}

Figure 3.1 shows no morphological difference between the larvae of Rasbora lateristriata and control Danio rerio with the larvae of Rasbora lateristriata and Danio rerio received treatment of D. alata with concentrations of $\mathrm{A}, \mathrm{B}$, and C. Although there was a delay in embryo development, successful larvae hatches showed the same morphology between control and treatment. The absence of morphological differences indicates that $\mathrm{D}$. alata is not a toxic material so that the larvae of Rasbora lateristriata and Danio rerio show normal growth, which is characterized by the formation of otic placodes, the presence of brain blocks and the presence of pigmentation in the embryo's body (OECD, 1997).

\section{CONCLUSIONS AND SUGGESTIONS}

D. alata has a significant effect on the development and function of the embryonic organs of Rasbora lateristriata and Danio rerio. Mean survival, mean hatchability, and mean heart rate in embryos exposed to D. alata with various concentrations significantly affected control and treatment. It can be concluded that D. alata can be toxic at high concentrations. Suggestions for the next research are to use dechorionated embryos, so that $\mathrm{D}$. alata exposure can directly hit the organs without obstructing the chorion as a protective sheath.

\section{ACKNOWLEDGMENTS}

Researchers would like to thank the parties who helped in completing this research. This research is financially supported by the 2020 Final Project Recognition Program (RTA), Gadjah Mada University.

\section{REFERENCES}

[1] W. M. F. Dufie, I. Oduro, W. O. Ellis, R. Asiedu, B. Maziya-Dixon. Potential health benefits of water yam (Dioscorea alata). Food \& function, 4 (10) (2013) 14961501. DOI: https://doi.org/10.1039/C3FO60064E

[2] G. Shui, L. P. Leong. Separation and determination of organic acids and phenolic compounds in fruit juices and drinks by high-performance liquid chromatography . Journal of chromatography A, 977 (1) (2002) 89-96. DOI: https://doi.org/10.1016/S0021-9673(02)01345-6

[3] S. Saklani, S. Chandra, A. P. Mishra. Nutritional profile, antinutritional profile and phytochemical screening of Garhwal Himalaya medicinal plant Dioscorea alata Tuber. International Journal of Pharmaceutical Sciences Review and Research, 23 (2) (2013) 42-46. 
[4] Y. W. Liu, H. F. Shang, C. K. Wang, F. L. Hsu, W. C. Hou. Immunomodulatory activity of dioscorin, the storage protein of yam (Dioscorea alata cv. Tainong No. 1) tuber. Food and Chemical Toxicology, 45 (11) (2007) 2312-2318. DOI: https://doi.org/10.1016/j.fct.2 007.06.009

[5] M. A. McAnuff, W. W. Harding, F. O. Omoruyi, H. Jacobs, E. Y. Morrison, H. N. Asemota. Hypoglycemic effects of steroidal sapogenins isolated from Jamaican bitter yam, Dioscorea polygonoides. Food and Chemical Toxicology, 43 (11) (2005) 1667-1672. DOI: https://doi.org/10.1016/j.fct.2005.05.008

[6] J. Y. Liu, F. L. Yang, C. P. Lu, Y. L. Yang, C. L. Wen, K. F. Hua, S. H. Wu. Polysaccharides from Dioscorea batatas induce tumor necrosis factor- $\alpha$ secretion via Toll-like receptor 4-mediated protein kinase signaling pathways. Journal of Agricultural and Food Chemistry, 56 (21) (2008) 9892-9898. DOI: https://doi.org/10.1021/jf8018722

[7] C. S. Sulastra, K. Khaerati. Toksisitas Akut Dan Lethal Dosis (Ld50) Ekstrak Etanol Uwi Banggai Ungu (Dioscorea Alata L.) Pada Tikus Putih (Rattus norvegicus). Jurnal Ilmiah Medicamento, 6 (1) (2020) 10-14. DOI: https://doi.org/10.36733/medicamento.v6i 1.715

[8] P. E. Ulloa, P. Iturra, R. Neira, C. Araneda. Zebrafish as a model organism for nutrition and growth: towards comparative studies of nutritional genomics applied to aquacultured fishes. Reviews in Fish Biology and Fisheries, 21 (4) (2011) 649-666.

[9] P. McGrath, C. Q. Li. Zebrafish: a predictive model for assessing drug-induced toxicity. Drug discovery today, 13 (9-10) (2008) 394-401. DOI:https://doi.org/ 10.1016/j.drudis.2008.03.002

[10] W. Vermerris, A. Saballos, G. Ejeta, N. S. Mosier, M. R. Ladisch, N. C. Carpita. Molecular breeding to enhance ethanol production from corn and sorghum stover. Crop Science, 47 (2007) S-142. DOI: https://doi .org/10.2135/cropsci2007.04.0013IPBS

[11] B. Retnoaji, R. Akiyama, T. Matta, Y. Bessho, T. Matsui. Retinoic acid controls proper head-to-trunk linkage in zebrafish by regulating an anteroposterior somitogenetic rate difference. Development, 141 (1) (2014) 158-165. DOI: 10.1242/dev.097568
[12] Z. Mohd-Shafiq, M. I. Mansor, M. R. Che-Salmah, M. S. Amir-Shahruddin. Assessment of suitability of Kerian River tributaries using length-weight relationship and relative condition factor of six freshwater fish species. Journal of Environment and Earth Science, 2 (3) (2012) 52-60.

[13] K. Madhu, R. Madhu, T. Retheesh. Broodstock development, breeding, embryonic development and larviculture of spine-cheek anemonefish, Premnas biaculeatus (Bloch, 1790). Indian Journal of Fisheries, 59 (1) (2012) 65-75.

[14] J. E. Podrabsky, C. L. Riggs, A L. Romney, S. C. Woll, J. T. Wagner, K. M. Culpepper, T. G. Cleaver. Embryonic development of the annual killifish Austrofundulus limnaeus: An emerging model for ecological and evolutionary developmental biology research and instruction. Developmental Dynamics, 246 (11) (2017) 779-801. DOI: https://doi.org/10.1002/dv dy. 24513

[15] K. Fent, C. J. Weisbrod, A. Wirth-Heller, U. Pieles. Assessment of uptake and toxicity of fluorescent silica nanoparticles in zebrafish (Danio rerio) early life stages. Aquatic toxicology, 100 (2) (2010) 218-228. DOI: https://doi.org/10.1016/j.aquatox.2010.02.019

[16] D. Djumanto, E. Setyobudi, A. A. Sentosa, N. Nirwati. Reproductive biology of the yellow rasbora (Rasbora lateristriata) inhabitat of the Ngrancah River, Kulon Progo Regency. Jurnal Perikanan Universitas Gadjah Mada, 10 (2) (2008) 261-275. DOI: https://doi .org/10.22146/jfs.8904

[17] M. R. Bhandari, J. Kawabata. Bitterness and toxicity in wild yam (Dioscorea spp.) tubers of Nepal. Plant Foods for Human Nutrition, 60 (3) (2005) $129-135$

[18] S. Shanthakumari, V. R. Mohan, J. de Britto. Nutritional evaluation and elimination of toxic principles in wild yam (Dioscorea spp.). Tropical and Subtropical Agroecosystems, 8 (3) (2008) 319-325.

[19] M. P. Borisova, A. A. Kataev, V. S. Sivozhelezov. Action of tannin on cellular membranes: Novel insights from concerted studies on lipid bilayers and native cells. Biochimica et Biophysica Acta (BBA)Biomembranes, 1861 (6) (2019) 1103-1111. DOI: https://doi.org/10.1016/j.bbamem.2019.03.017 
[20] R. N. Granito, A. C. M. Renno, H. Yamamura, M. C. de Almeida, P. L. M. Ruiz, D. A. Ribeiro. Hydroxyapatite from fish for bone tissue engineering: A promising approach. International journal of molecular and cellular medicine, 7 (2) (2018) 80. DOI:10.22088/I JMCM.BUMS.7.2.80

[21] N. D. Rawlings, D. P. Tolle, A. J. Barrett. Evolutionary families of peptidase inhibitors. Biochem Ical Journal, 378 (3) (2004) 705-716. DOI: https://doi .org/10.1042/bj20031825

[22] S. T. Freer, J. Kraut, J. D. Robertus, H. T. Wright. Chymotrypsinogen: 2, 5- $\AA$ crystal structure, compariso $n$ with $\alpha$-chymotrypsin, and implications for zymogen activation. Biochemistry, 9 (9) (1970) 1997-2009. DOI: https://doi.org/10.1021/bi00811a022

[23] H. Al-Kandari, N. Younes, O. Al-Jamal, Z. Z. Zakaria, H. Najjar, F. Alserr, G. K. Nasrallah. Ecotoxicological assessment of thermally-and hydrogen-reduced graphene oxide/TiO2 photocatalytic nanocomposites using the zebrafish embryo model. Nanomaterials, 9 (4) (2019) 488. DOI: https:// doi.org/10.3390/nano9040488

[24] J. M. Hillegass, A. Shukla, S. A. Lathrop, M. B. MacPherson, N. K. Fukagawa, B. T. Mossman. Assessing nanotoxicity in cells in vitro. Wiley Interdisciplinary Reviews: Nanomedicine and Nanobiotechnology, 2 (3) (2010) 219-231. DOI: https:// doi.org/10.1002/wnan.54

[25] T. S. Rothenbücher, J. Ledin, D. Gibbs, H. Engqvist, C. Persson, G. Hulsart-Billström. Zebrafish embryo as a replacement model for initial biocompatibility studies of biomaterials and drug delivery systems. Acta biomaterialia, 100 (2019) 235243. DOI: https://doi.org/10.1016/j.actbio.2019.09.038

[26] E. Heckel, F. Boselli, S. Roth, A. Krudewig, H. G. Belting, G. Charvin, J. Vermot. Oscillatory flow modulates mechanosensitive klf2a expression through trpv4 and trpp2 during heart valve development. Current Biology, 25 (10) (2015) 13541361. DOI: https://doi.org/10.1016/j.cub.2015.03.038

[27] H. C. Yalcin, A. Amindari, J. T. Butcher, A. Althani, M. Yacoub. Heart function and hemodynamic analysis for zebrafish embryos. Developmental Dynamics, 246 (11) (2017) 868-880. DOI: https://doi. org/10.1002/dvdy.24497
[28] J. P. Velotta, Z. A. Cheviron. Remodeling ancestral phenotypic plasticity in local adaptation: A new framework to explore the role of genetic compensation in the evolution of homeostasis. Integrative and comparative biology, 58 (6) (2018) 1098-1110. DOI: https://doi.org/10.1093/icb/icy117

[29] D. A. Keir, M. B. Badrov, G. Tomlinson, C. F. Notarius, D. S. Kimmerly, P. J. Millar, J. S. Floras. Influence of sex and age on muscle sympathetic nerve activity of healthy normotensive adults. Hypertension, 7 6 (3) (2020) 997-1005. DOI: https://doi.org/10.1161/H YPERTENSIONAHA.120.15208 